\title{
Clinical features of patients with lung cancer accompanied by thromboembolism or disseminated intravascular coagulation
}

This article was published in the following Dove Press journal:

Therapeutics and Clinical Risk Management

\author{
Nobuhiro Kanaji \\ Hitoshi Mizoguchi' \\ Takuya Inoue' \\ Akira Tadokoro ${ }^{2}$ \\ Naoki Watanabe' \\ Tomoya Ishii' \\ Yasunori Tojo ${ }^{2}$ \\ Masahiro Yamaguchi ${ }^{3}$ \\ Norimitsu Kadowaki' \\ 'Department of Internal \\ Medicine, Division of Hematology, \\ Rheumatology and Respiratory \\ Medicine, Faculty of Medicine, \\ Kagawa University, ${ }^{2}$ Department \\ of Respiratory Medicine, National \\ Hospital Organization Takamatsu \\ Medical Center, ${ }^{3}$ Department of \\ Internal Medicine, Shodoshima \\ Central Hospital, Kagawa, Japan
}

Correspondence: Nobuhiro Kanaji Department of Internal Medicine, Division of Hematology, Rheumatology and Respiratory Medicine, Faculty of Medicine, Kagawa University, I750-I Ikenobe, Miki-cho, Kita-gun, Kagawa 76I-0793, Japan

Tel $+8|8789| 2 \mid 45$

Fax +8I $8789 \mid 2147$

Email kanaji@med.kagawa-u.ac.jp
Purpose: Thromboembolism (TE) and disseminated intravascular coagulation (DIC) are often present concomitantly. This study aimed to investigate the clinical features of patients with lung cancer and TE and/or DIC.

Patients and methods: Data on 716 patients with pathologically confirmed diagnoses of lung cancer were retrospectively analyzed for TE/DIC.

Results: TE was identified in 16 patients $(2.2 \%)$ and DIC was identified in $5(0.7 \%)$ during the diagnosis of cancer. TE was more often observed in adenocarcinoma (4.0\%). Both TE and DIC were more often observed in stage IV ( $4.7 \%$ and $1.5 \%$, respectively). In patients with stage IV adenocarcinoma who received some systemic treatment, overall survival (OS) was significantly shorter in patients with TE (median 280 days) and with DIC (72 days) than in non-TE/DIC patients (538 days). Multivariate analysis showed that older age, poor performance status, greater number of metastatic organs, no $E G F R$ mutation/ALK fusion, presence of interstitial lung disease, and DIC were poor prognostic factors for OS. In 339 patients in stage IV, 25 (7.4\%) and $21(6.2 \%)$ patients had TE and DIC, respectively, during the course. Six patients exhibited both TE and DIC. TE was more often observed in adenocarcinoma (20 of 196 patients; $10.2 \%$ ). Patients with DIC had extremely shorter survival (median 13 days) after onset. Cancer control by systemic therapy, such as chemotherapy and molecular-targeted therapy, contributed to long survival.

Conclusion: Patients with TE/DIC had shorter OS than patients without TE/DIC. Control of lung cancer by systemic therapy was important for longer survival after the onset of events.

Keywords: deep vein thrombosis, pulmonary embolism, survival, Trousseau's syndrome, venous thrombotic event, prognosis

\section{Introduction}

Thromboembolism (TE) and disseminated intravascular coagulation (DIC) are often present concomitantly in lung cancer. TE includes thrombophlebitis, deep vein thrombosis (DVT), pulmonary embolism (PE), nonbacterial thrombotic endocarditis (NBTE), and arterial embolism. Among cancer-associated TE (often called Trousseau's syndrome), venous thrombotic event (VTE; DVT and PE) has been most frequently encountered and therefore studied. ${ }^{1,2}$ A study reported that 1-year cumulative VTE incidence was 3.0\% in 91,933 patients with lung cancer. ${ }^{3}$ Predictors for developing VTE included being male, younger age, obesity, chronic medical comorbidities, advanced stage, and adenocarcinoma histology. ${ }^{3-5}$ It has not been fully reported regarding clinical features of lung cancer with more wide meaning of TE including NBTE and arterial embolism. 
DIC is an acquired syndrome characterized by the intravascular activation of coagulation with the loss of localization arising from different causes. ${ }^{6}$ In a report of 1,117 patients with solid tumors, 76 (6.8\%) patients were diagnosed with DIC and the occurrence of DIC appeared to be an independent factor for the survival of patients with solid tumors. ${ }^{7}$ Despite the fact that DIC should be common in lung cancer, only limited data have been published regarding DIC and lung cancer $^{8}$ and information on survival in patients with lung cancer and DIC has not been fully reported till date.

Because TE and DIC are related to hypercoagulopathy, it may not be preferable to consider those conditions separately. We hypothesized that TE/DIC is related to certain clinical features in patients with lung cancer. To clarify this hypothesis, we retrospectively assessed the incidences and risk factors of TE/DIC and compared survival in patients with TE/DIC with that in patients without TE/DIC. In addition, the influence of treatments on survival after the onset of TE/DIC was also assessed.

\section{Patients and methods}

\section{Patients}

Patients with pathologically confirmed lung cancer who presented to the Department of Internal Medicine, Kagawa University Hospital, between January 2007 and December 2016 were retrospectively identified, and relevant clinical and laboratory data were collected from their medical records (764 patients). Patients who (1) had been receiving any treatment for anticoagulation at lung cancer diagnosis (29 patients), (2) had another concomitant active malignancy (18 patients), or (3) had concomitant antiphospholipid syndrome (one patient) were excluded. Thus, 716 patients were included in this study. All lung cancers were staged according to the seventh edition of the TNM classification of malignant tumors. Patients with stage IV (339 patients) were followed up to assess the final frequency of TE and/or DIC during the total course of cancer.

This study was approved by the Research Ethics Committee of Kagawa University (no H29-051). All procedures performed in the study involving human participants were in accordance with the 1964 Declaration of Helsinki and its later amendments covering patient data confidentiality. Informed consent was not obtained from all individual participants because this study is retrospective and includes patients who already died. However, our institute presented the study design officially, which provided the chance to all people to check it and reject the participation in this study. This procedure was also approved by the Research Ethics Committee of Kagawa University.

\section{Definition of TE and DIC}

The occurrence of TE was suspected by symptoms and/or laboratory examinations such as high level of D dimer and confirmed by radiologic findings (mostly enhanced computerized tomography [CT] scan). Cases clinically diagnosed with only symptoms and blood examination, without radiologic evidence, were not diagnosed with TE in this study. In addition, DVT associated with central venous catheter or with direct tumor invasion into the vein was also excluded from the TE group in this study. We defined TE and/or DIC "at lung cancer diagnosis" when TE and/or DIC occurred within 1 month before and after lung cancer diagnosis. No routine "screening" radiologic examinations to detect asymptomatic TE were performed in this study.

DIC diagnosis was performed according to the Japanese Ministry of Health and Welfare's DIC diagnostic criteria, in which underlying disease, clinical symptoms, platelet count, fibrinogen, fibrin degradation products, and prothrombin time are scored. ${ }^{9}$

\section{Statistical analyses}

Overall survival (OS) was defined as the time between the date of diagnosis and the date of death from any cause. OS curves were constructed by the Kaplan-Meier method, and differences in survivals were compared using the log-rank test. Fisher's exact test and Student's $t$-test were used to analyze patient's characteristics. All statistical analyses were conducted using Ekuseru-Toukei 2015 (Social Survey Research Information, Tokyo, Japan).

\section{Results}

\section{TE and/or DIC at lung cancer diagnosis}

Relevant characteristics of patients at lung cancer diagnosis are shown in Table 1. TE was identified in $16(2.2 \%)$ of the 716 patients, and DIC was identified in five $(0.7 \%)$ patients. Two patients had both conditions concomitantly. Among TE patients, DVT was observed in 12 patients, PE was observed in six patients, arterial thrombosis was observed in five patients (three patients with cerebral infarctions, one patient with acute myocardial infarction, and one patient with renal infarction), and NBTE was observed in one patient. Four patients had both DVT and PE, and two patients had DVT, $\mathrm{PE}$, and arterial thrombosis.

Patients with TE were significantly younger than those without TE/DIC (60 vs 70 years). Performance status (PS) was worse in patients with either TE or DIC than in patients without TE/DIC. TE was significantly more often observed in adenocarcinoma than other histology $(4.0 \%$ in adenocarcinoma, $P=0.0006$ ), whereas no patients with squamous 
Table I Patient's characteristics at the diagnosis with lung cancer

\begin{tabular}{|c|c|c|c|c|c|}
\hline Characteristics & $\begin{array}{l}\text { Non-TE/DIC } \\
(n=697)\end{array}$ & $\begin{array}{l}\text { TE } \\
(n=16)\end{array}$ & $\begin{array}{l}\text { P-value } \\
\text { (vs non-TE/DIC) }\end{array}$ & $\begin{array}{l}\text { DIC } \\
(n=5)\end{array}$ & $\begin{array}{l}\text { P-value } \\
\text { (vs non-TE/DIC) }\end{array}$ \\
\hline \multicolumn{6}{|l|}{ Age (years) } \\
\hline Average (range) & 70 (23-92) & $60(4 \mid-8 I)$ & 0.0063 & $74(68-8 I)$ & 0.1912 \\
\hline \multicolumn{6}{|l|}{ Gender } \\
\hline Male & 508 & 9 & 0.1588 & 2 & 0.1291 \\
\hline Female & 189 & 7 & & 3 & \\
\hline \multicolumn{6}{|l|}{ Smoking status } \\
\hline Never & 161 & 6 & 0.2288 & 2 & 0.3317 \\
\hline Ever & 533 & 10 & & 3 & \\
\hline $\begin{array}{l}\text { Pack-year, } \\
\text { average }\end{array}$ & 57 & 35 & 0.0308 & 63 & 0.8719 \\
\hline Unknown & 3 & 0 & & 0 & \\
\hline \multicolumn{6}{|l|}{ PS } \\
\hline $0-1$ & 577 & 10 & 0.0468 & 2 & 0.0401 \\
\hline $2-4$ & 120 & 6 & & 3 & \\
\hline \multicolumn{6}{|l|}{ ILD } \\
\hline Yes & $|5|$ & 3 & 1.0000 & 2 & 0.2996 \\
\hline No & 546 & 13 & & 3 & \\
\hline \multicolumn{6}{|l|}{ Histology } \\
\hline Small & 93 & I (I.0\%) & 0.7087 & $2(2.1 \%)$ & 0.1378 \\
\hline Adenocarcinoma & 360 & 15 (4.0\%) & 0.0006 & $3(0.8 \%)$ & 1.0000 \\
\hline Squamous & 160 & 0 & 0.0296 & 0 & 0.5938 \\
\hline Others & 21 & 0 & 1.0000 & 0 & 1.0000 \\
\hline NSCLC, NOS & 63 & 0 & 0.3848 & 0 & 1.0000 \\
\hline \multicolumn{6}{|l|}{ Stage } \\
\hline I & 147 & 0 & 0.0534 & 0 & 0.5895 \\
\hline II & 68 & 0 & $0.387 \mid$ & 0 & 1.0000 \\
\hline III & 162 & 0 & 0.0298 & 0 & 0.5947 \\
\hline IV & 320 & 16 (4.7\%) & $<0.0001$ & 5 (I.5\%) & 0.0209 \\
\hline \multicolumn{6}{|c|}{ Number of metastatic organs in stage IV } \\
\hline Average (range) & 1.89 (I-9) & $2.94(I-9)$ & 0.0422 & $3.20(I-5)$ & 0.1764 \\
\hline
\end{tabular}

Abbreviations: DIC, disseminated intravascular coagulation; ILD, interstitial lung disease; NOS, not otherwise specified; NSCLC, non-small-cell lung cancer; PS, performance status; TE, thromboembolism.

cell carcinoma had concomitant $\mathrm{TE}$ at cancer diagnosis. Both TE and DIC were significantly more often observed in stage IV (4.7\% and 1.5\%, respectively). All TE and DIC were observed in patients with stage IV. The number of metastatic organs in stage IV was higher in TE patients than in non-TE/ DIC patients (averages 1.89 vs $2.94, P=0.0422$ ).

\section{Shorter OS in patients with TE or DIC}

OS is generally dependent on histology, clinical stage, and treatment option in patients with lung cancer. Because TE was more frequently observed in stage IV adenocarcinoma, we assessed OS in those patients who received systemic treatment ( $\mathrm{n}=177)$. Kaplan-Meier survival curves for these patients showed a significantly shorter median OS in TE patients (Figure 1A; 280 vs 538 days, $P=0.0454$ ) and in DIC (Figure 1B; 72 vs 528 days, $P<0.0001$ ) than in non-TE/ DIC patients.

Univariate analysis by log-rank test identified that older age, male gender, poor PS, a high number of metastatic organs ( $>3$ organs), no epidermal growth factor receptor (EGFR) mutation or anaplastic lymphoma kinase $(A L K)$ fusion, presence of interstitial lung disease (ILD), TE, and DIC were associated with poor OS (Table 2). Multivariate analysis by Cox's proportional hazards model showed that older age, poor PS, a high number of metastatic organs, no EGFR mutation/ALK fusion, presence of ILD, and DIC were poor prognostic factors for OS.

\section{TE and/or DIC occurred during the treatment period}

We investigated the frequency of TE and/or DIC during the total treatment period among 339 patients in stage IV. Apart from during the diagnosis of lung cancer, TE and DIC also appeared in nine and 16 patients, respectively, during the course. Accordingly, 25 (7.4\%) and 21 (6.2\%) patients had TE and DIC, respectively (Table 3 ). Among TE patients, DVT was observed in 17 patients, PE was observed in eight patients, and arterial thrombosis was observed 

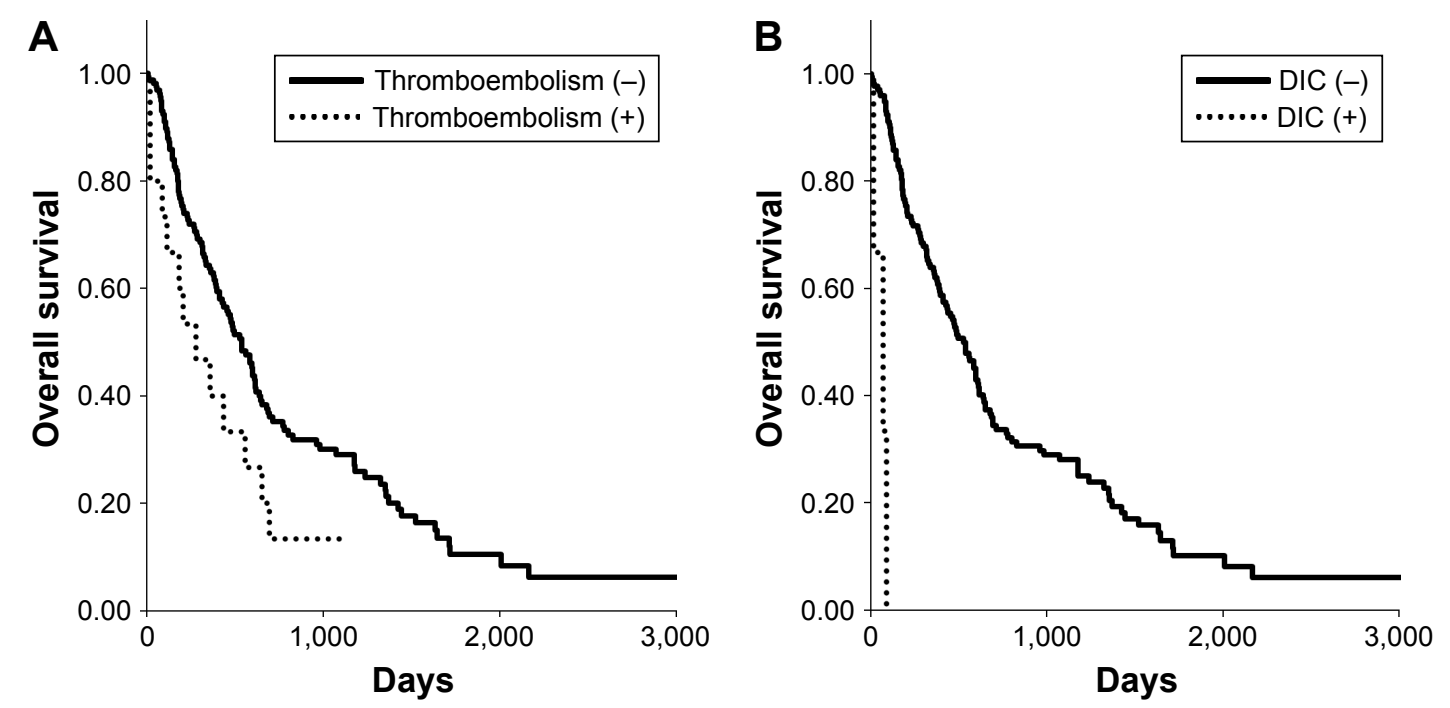

Figure I Kaplan-Meier curves of overall survival in patients with stage IV adenocarcinoma who received some systemic treatment, dependent on the status of (A) thromboembolism and (B) DIC observed at cancer diagnosis.

Abbreviation: DIC, disseminated intravascular coagulation.

in eight patients (additionally two patients had cerebral infarctions and one patient had acute myocardial infarction). TE was still more often observed in adenocarcinoma (20 of 196 patients; $10.2 \%, P=0.0343$ ), whereas no obvious difference in the frequency of DIC was observed among histologies. Six patients exhibited both TE and DIC (four patients had adenocarcinoma and two patients had squamous cell carcinoma). Of the 25 patients with TE, 18 (72\%) patients

Table 2 Risk factors associated with overall survival in patients with stage IV adenocarcinoma

\begin{tabular}{|c|c|c|c|c|c|}
\hline \multirow[t]{2}{*}{ Characteristics } & \multirow[t]{2}{*}{$\mathbf{n}$} & \multirow{2}{*}{$\begin{array}{l}\text { Median } \\
\text { (days) }\end{array}$} & \multirow{2}{*}{$\begin{array}{l}\text { Univariate analysis } \\
P \text {-value }\end{array}$} & \multicolumn{2}{|c|}{ Multivariate analysis } \\
\hline & & & & HR (95\% Cl) & P-value \\
\hline \multicolumn{6}{|l|}{ Age (years) } \\
\hline Older ( $\geq 75$ years) & 46 & 314 & 0.0379 & $1.82(1.18-2.78)$ & 0.0063 \\
\hline Younger ( $<75$ years) & $|3|$ & 584 & & & \\
\hline \multicolumn{6}{|l|}{ Gender } \\
\hline Male & 101 & 393 & 0.0106 & $1.59(0.95-2.66)$ & 0.0759 \\
\hline Female & 76 & 638 & & & \\
\hline \multicolumn{6}{|l|}{ Smoking status } \\
\hline Ever & 112 & 486 & 0.4422 & $0.72(0.43-1.23)$ & 0.2322 \\
\hline Never & 65 & 538 & & & \\
\hline \multicolumn{6}{|l|}{ PS } \\
\hline $2-4$ & 35 & 176 & $<0.0001$ & $2.98(1.89-4.70)$ & $<0.0001$ \\
\hline $0-1$ & 142 & 599 & & & \\
\hline \multicolumn{6}{|c|}{ Number of metastatic organs } \\
\hline$\geq 3$ & 52 & 360 & 0.0039 & $1.68(1.10-2.55)$ & 0.0161 \\
\hline $1-2$ & 125 & 596 & & & \\
\hline \multicolumn{6}{|c|}{ EGFR mutation or ALK fusion } \\
\hline No & 108 & 396 & 0.0001 & $\mathrm{I} .85(\mathrm{I} .22-2.8 \mathrm{I})$ & 0.0036 \\
\hline Yes & 69 & 679 & & & \\
\hline \multicolumn{6}{|l|}{ ILD } \\
\hline Yes & 25 & 267 & 0.0116 & $1.90(1.11-3.26)$ & 0.0197 \\
\hline No & 152 & 539 & & & \\
\hline \multicolumn{6}{|l|}{ TE } \\
\hline Yes & 15 & 280 & 0.0454 & $1.06(0.55-2.08)$ & 0.8557 \\
\hline No & 162 & 538 & & & \\
\hline \multicolumn{6}{|l|}{ DIC } \\
\hline Yes & 3 & 72 & $<0.0001$ & 26.75 (6.58-108.7I) & $<0.0001$ \\
\hline No & 174 & 528 & & & \\
\hline
\end{tabular}

Abbreviations: ALK, anaplastic lymphoma kinase; DIC, disseminated intravascular coagulation; EGFR, epidermal growth factor receptor; ILD, interstitial lung disease; $\mathrm{PS}$, performance status; TE, thromboembolism. 
Table 3 Thromboembolism and/or DIC occurred during total treatment period of patients with stage IV lung cancer

\begin{tabular}{|c|c|c|c|c|c|}
\hline \multirow[t]{2}{*}{ Histology } & \multirow[t]{2}{*}{$\mathbf{n}$} & \multicolumn{2}{|l|}{ TE } & \multicolumn{2}{|l|}{ DIC } \\
\hline & & n (DVT/PE/arterial) ${ }^{a}$ & $P$-value & $\mathbf{n}$ & $P$-value \\
\hline Small & 58 & $2(3.4 \%)(1 / 0 / 1)$ & 0.3991 & $4(6.9 \%)$ & 0.7688 \\
\hline Adenocarcinoma & 196 & $20(10.2 \%)(15 / 8 / 5)$ & 0.0343 & II (5.6\%) & 0.6544 \\
\hline Squamous & 49 & $2(4.1 \%)(0 / 0 / 2)$ & 0.5526 & $5(10.2 \%)$ & 0.2215 \\
\hline Others & 7 & 0 & 1.0000 & 0 & 1.0000 \\
\hline NSCLC, NOS & 29 & I (3.4\%) (I/0/0) & 0.7083 & I (3.4\%) & 1.0000 \\
\hline Total & 339 & 25 (7.4\%) (I7/8/8) & & $21(6.2 \%)$ & \\
\hline
\end{tabular}

Note: aEach sum may not in accordance with the total number.

Abbreviations: DIC, disseminated intravascular coagulation; DVT, deep vein thrombosis; NOS, not otherwise specified; NSCLC, non-small-cell lung cancer; PE, pulmonary embolism; TE, thromboembolism.

had symptoms, such as chest pain and swelling of lower extremities, which led to TE diagnosis. Seven patients had no subjective symptoms, and TE was discovered by CT scan for the assessment of cancer (three patients) or the examination of elevation of D dimer (four patients). Of the 21 patients with DIC, 15 patients had some symptoms associated with DIC such as bleeding. Remaining six patients had no symptoms directly related to DIC, and laboratory data such as decreased number of platelets led to the diagnosis of DIC. Importantly, all DIC events occurred with cancer progression including during the diagnosis of cancer and never occurred with good disease control.

\section{Influence of treatments on survival after the onset of TE/DIC}

Survivals after the onset of TE and/or DIC are summarized in Table 4. The median survival after the onset of TE was 223 days, whereas survival after the onset of DIC was significantly shorter (13 days, $P<0.0001$ compared with TE, Figure 2A). Systemic therapy, such as chemotherapy and molecular-targeted therapy, was performed in 26 of the 40 patients. Survival after the onset of TE/DIC in 14 patients who had disease control (stable disease [SD] or partial response [PR]) was significantly longer than in those who had progressive disease or who received no systemic therapy

Table 4 Risk factors associated with survival after the onset of thromboembolism and/or DIC

\begin{tabular}{|c|c|c|c|c|c|}
\hline \multirow[t]{2}{*}{ Characteristics } & \multirow[t]{2}{*}{$\mathbf{n}$} & \multirow{2}{*}{$\begin{array}{l}\text { Median } \\
\text { (days) }\end{array}$} & \multirow{2}{*}{$\frac{\text { Univariate analysis }}{P \text {-value }}$} & \multicolumn{2}{|c|}{ Multivariate analysis } \\
\hline & & & & HR (95\% Cl) & $P$-value \\
\hline \multicolumn{6}{|l|}{ Age (years) } \\
\hline Older ( $\geq 75$ years) & 6 & 16 & 0.5159 & $0.97(0.31-3.03)$ & 0.9627 \\
\hline Younger ( $<75$ years) & 34 & 38 & & & \\
\hline \multicolumn{6}{|c|}{ EGFR mutation or ALK fusion } \\
\hline No & 32 & 28 & 0.0469 & $3.21(1.16-8.92)$ & 0.0249 \\
\hline Yes & 8 & 199 & & & \\
\hline \multicolumn{6}{|l|}{ ILD } \\
\hline Yes & 10 & 38 & 0.3639 & $0.73(0.23-2.33)$ & 0.5903 \\
\hline No & 30 & 38 & & & \\
\hline \multicolumn{6}{|l|}{ Histology } \\
\hline Small & 6 & 28 & & & \\
\hline Adenocarcinoma & 27 & 118 & 0.0202 & $0.42(0.13-1.33)$ & 0.1395 \\
\hline Squamous & 12 & 12 & & & \\
\hline \multicolumn{6}{|l|}{ TE/DIC } \\
\hline TE & 25 & 223 & & & \\
\hline DIC & 21 & 13 & $<0.000 \mathrm{I}$ & $8.45(2.87-24.89)$ & 0.0001 \\
\hline \multicolumn{6}{|c|}{ Chemotherapy or molecular-targeted therapy, response } \\
\hline No & 14 & 8 & $<0.0001$ & $9.69(2.68-35.11)$ & 0.0005 \\
\hline Yes, PD & 12 & 28 & & & \\
\hline Yes, SD or PR & 14 & 365 & & & \\
\hline \multicolumn{6}{|l|}{ Anticoagulation therapy } \\
\hline No & 8 & 8 & 0.0027 & $2.45(0.85-7.06)$ & 0.0977 \\
\hline Yes & 32 & 83 & & & \\
\hline
\end{tabular}

Abbreviations: ALK, anaplastic lymphoma kinase; DIC, disseminated intravascular coagulation; EGFR, epidermal growth factor receptor; ILD, interstitial lung disease; $\mathrm{PD}$, progressive disease; PR, partial response; $\mathrm{SD}$, stable disease; TE, thromboembolism. 

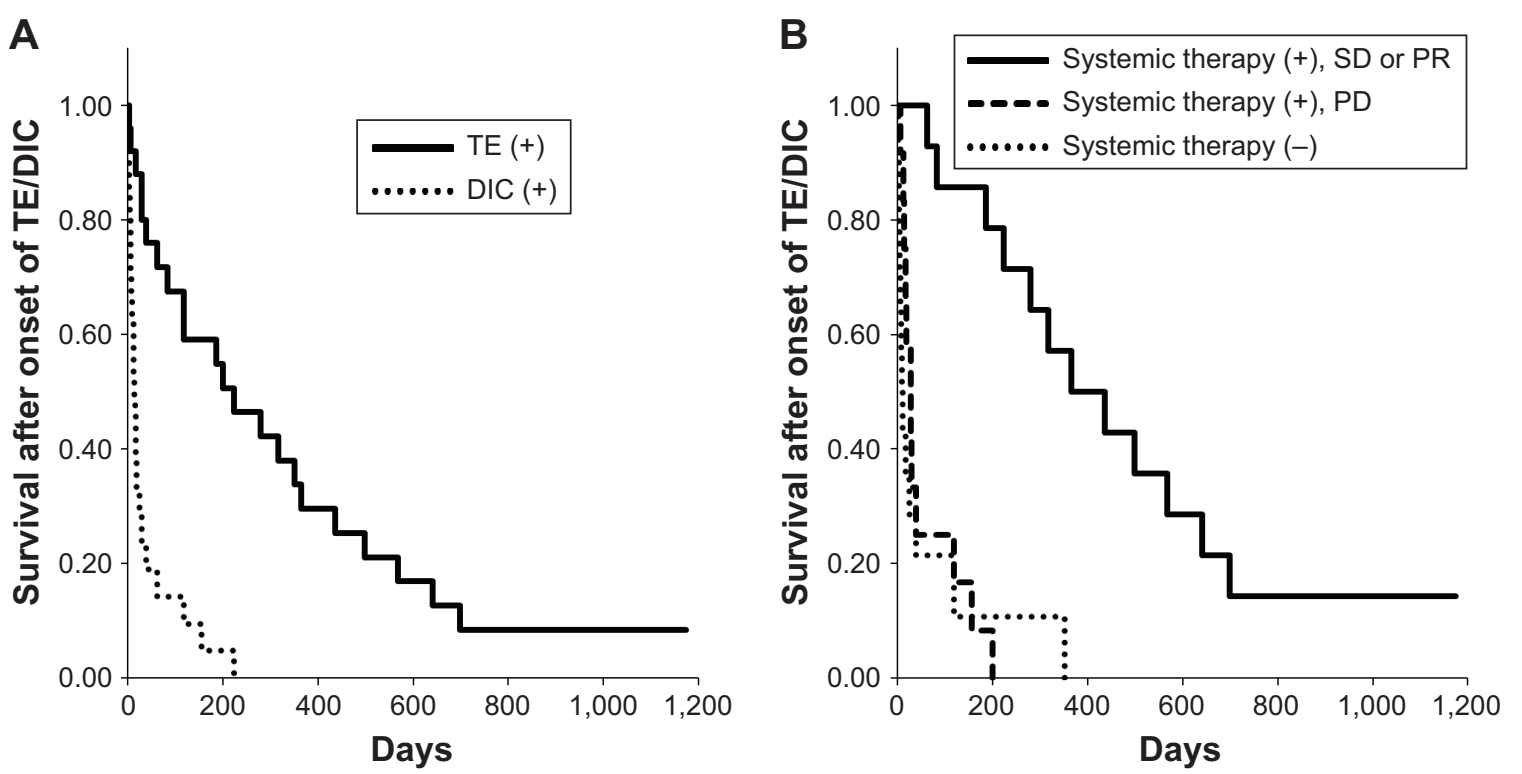

Figure 2 Kaplan-Meier curves of survival after the onset of TE and/or DIC occurred during the total course, dependent on the status of (A) event type and (B) systemic therapy (chemotherapy or molecular-targeted therapy).

Abbreviations: DIC, disseminated intravascular coagulation; PD, progressive disease; PR, partial response; SD, stable disease; TE, thromboembolism.

(median 365, 28, and 8 days, respectively, $P<0.0001$, Table 4 and Figure 2B). Thirty-two patients also received some anticoagulation/thrombosis therapy (heparin/low-molecularweight heparin [LMWH] in 20 patients, gabexate mesilate in seven patients, warfarin in six patients, edoxaban tosilate hydrate in four patients, and antiplatelet agents including aspirin and cilostazol in four patients for arterial thrombosis), while eight patients did not receive any anticoagulation/ thrombosis agents because of active bleeding or terminal stage. No obvious difference was observed between warfarin and edoxaban tosilate hydrate on survival. Multivariate analysis showed no $E G F R$ mutation/ $A L K$ fusion, DIC, and no systemic therapy or no response to systemic therapy was the poor prognostic factor for survival after the onset of TE/DIC in patients with those events. Although use of anticoagulation/thrombosis therapy was better for survival as assessed by univariate analysis, the statistical significance disappeared when assessed by multivariate analysis.

\section{Discussion}

In the present study, we demonstrated that 1) the incidence of TE was higher in adenocarcinoma and in stage IV, 2) the presence of TE during the diagnosis of lung cancer was associated with shorter survival, 3) DIC was observed at the late phase during the treatment period rather than at the early phase (at cancer diagnosis), 4) DIC occurrence was associated with significantly shorter survival, and 5) successful systemic therapy for lung cancer was essential for long survival after the onset of TE/DIC.
TE incidence varied among the conditions $(2.2 \%$ of all cancers during diagnosis and $10.2 \%$ of stage IV adenocarcinomas during the total course), which is comparable with the results of previous reports $(6.1 \%-13.6 \%$ of non-small-cell lung cancer). ${ }^{4,5,10}$ It has been reported that mucins produced from adenocarcinomas may play an important role in the development of TE by activating factor X., , 11,12 Injecting carcinoma mucins into mice triggered the generation of platelet-rich microthrombi. ${ }^{11}$ Mucin-producing potential was a predisposing factor for TE in pancreatic carcinoma. ${ }^{12}$ TE frequency might be underestimated, because radiologic assessment of TE was not always performed during the diagnosis of cancer or in patients with DIC or at terminal stage. In addition, asymptomatic cases were usually not examined for TE. TE was diagnosed in $72 \%$ of patients with subjective symptoms, and some patients died without recovery from TE. Although TE was associated with shorter survival by univariate analysis, it was not an independent prognostic factor by multivariate analysis. We speculate that $E G F R$ mutations or $A L K$ fusions are the biggest factors because these driver mutations were positive for five patients with TE and all five patients received molecular-targeted therapy resulting in longer survival. Regular-enhanced CT examination, including that of the lower extremities, may detect asymptomatic TE. It is a future problem to determine if early detection of TE contributes to prolonged survival.

Although DVT was most common in cancer-associated $\mathrm{TE}$, arterial thrombosis was observed in eight of the 25 patients in stage IV lung cancer, indicating that arterial thrombosis is 
also not rare. Pulmonologists need to pay attention to arterial thrombosis as one feature of cancer-associated TE.

Compared with VTE, data reporting DIC in lung cancer are scarce. ${ }^{8}$ In the present study, DIC occurred in 21 cases $(6.2 \%)$ of 339 stage IV patients. This incidence is similar to that of a previous report (11 of 153 lung cancer cases), ${ }^{7}$ although postmortem examination showed higher incidence of DIC (18 of 43 autopsies). ${ }^{13}$ DIC occurrence appears to be an independent factor for survival among patients with solid tumors or hematologic malignancies. ${ }^{7,13}$ The present study has given evidence, for the first time, that DIC was an independent poor prognostic factor on the survival of patients with lung cancer. In addition, systemic therapy for lung cancer was important for longer survival after the onset of TE/DIC. In contrast, no systemic therapy or failure of cancer control with systemic therapy resulted in extremely shorter survival.

Chronic DIC is well known to sometimes be observed in Trousseau's syndrome; ${ }^{14}$ moreover, the essence of DIC is hypercoagulopathy. Cancer cells activate coagulation through multiple mechanisms such as productions of tissue factor (TF) and inflammatory cytokines. ${ }^{1,15}$ TF directly converts factor VII to factor VIIa, resulting in the activation of the coagulation cascade. ${ }^{1}$ Inflammatory cytokines can induce TF from vascular cells and other types of cells such as monocytes and macrophages. In the present study, six patients exhibited both TE and DIC. Similarly, a previous study reported that TE was diagnosed in $22.5 \%$ of 89 DIC cases, including 10 lung cancers. ${ }^{13}$ However, theoretically, all patients diagnosed with DIC should have intravascular coagulation, that is, thrombosis. Including the present study, TE was generally diagnosed by radiologic evidence. In this regard, patients with DIC without evidence of TE might have microthrombosis and all these patients might be regarded to have Trousseau's syndrome. In fact, in cases with even clinically unsuspected DIC, microthrombus formation in multiple organs could be detected by postmortem examination. ${ }^{16}$

The present study revealed the usefulness of systemic therapy for lung cancer on the improvement of TE/DIC and long survival. However, it has been reported that chemotherapy and surgery have been related to the development of TE in patients with cancer. ${ }^{17}$ These findings are not always contradictory. It can be easily predicted that the release of a high amount of TF and other components from cancer cells due to apoptosis leads to hypercoagulation, that is, development of TE. However, when TE has already occurred, effective chemotherapy is necessary to reduce its source of supply, with careful attention paid to the deterioration of TE. Although the use of anticoagulation/thrombosis therapy including heparin/LMWH, oral anticoagulants, and antiplatelet agents was better for survival assessed by univariate analysis, the statistical significance disappeared when this intervention was assessed by multivariate analysis. This finding might be due to a few numbers of cases. In other words, other factors including systemic anticancer therapy have greater effect on longer survival.

This study also provides evidence regarding ILD on the survival of lung cancer patient. OS was significantly shorter in adenocarcinoma patients with ILD than in those without ILD (median 267 vs 539 days, respectively), and the presence of ILD was an independent poor prognostic factor for OS, which is consistent with findings of previous reports. ${ }^{18-20}$

The limitations of this study are as follows. First, this was a retrospective, single-center study. A prospective, multicenter study is desirable to further investigate clinical features of TE and DIC in patients with lung cancer, including their accurate frequencies. Second, some clinical questions remain unclear, including the usefulness of early detection of asymptomatic TE cases and the efficacy of anticoagulation/ thrombosis therapy.

\section{Conclusion}

This study showed the frequency of TE/DIC in patients with lung cancer and that patients with TE/DIC have shorter OS than patients without TE/DIC. TE is often observed in patients with adenocarcinoma during the diagnosis of cancer, whereas DIC is more often observed in the late advanced phase and results in significantly shorter survival. Lung cancer control by systemic therapy such as chemotherapy and molecular-targeted therapy is essential for long survival after the onset of TE/DIC.

\section{Acknowledgment}

The authors thank Ms Takimi Tamaki for her support.

\section{Disclosure}

The authors report no conflicts of interest in this work.

\section{References}

1. Ikushima S, Ono R, Fukuda K, Sakayori M, Awano N, Kondo K. Trousseau's syndrome: cancer-associated thrombosis. Jpn J Clin Oncol. 2016;46(3):204-208.

2. Kanaji N, Watanabe N, Kita N, et al. Paraneoplastic syndromes associated with lung cancer. World J Clin Oncol. 2014;5(3):197-223.

3. Tagalakis V, Levi D, Agulnik JS, Cohen V, Kasymjanova G, Small D. High risk of deep vein thrombosis in patients with non-small cell lung cancer: a cohort study of 493 patients. J Thorac Oncol. 2007;2(8): 729-734.

4. Hicks LK, Cheung MC, Ding K, et al. Venous thromboembolism and nonsmall cell lung cancer: a pooled analysis of National Cancer Institute of Canada Clinical Trials Group trials. Cancer. 2009;115(23): $5516-5525$. 
5. Chew HK, Davies AM, Wun T, Harvey D, Zhou H, White RH. The incidence of venous thromboembolism among patients with primary lung cancer. J Thromb Haemost. 2008;6(4):601-608.

6. Taylor FB Jr, Toh CH, Hoots WK, Wada H, Levi M; Scientific Subcommittee on Disseminated Intravascular Coagulation (DIC) of the International Society on Thrombosis and Haemostasis (ISTH). Towards definition, clinical and laboratory criteria, and a scoring system for disseminated intravascular coagulation. Thromb Haemost. 2001;86(5): 1327-1330.

7. Sallah S, Wan JY, Nguyen NP, Hanrahan LR, Sigounas G. Disseminated intravascular coagulation in solid tumors: clinical and pathologic study. Thromb Haemost. 2001;86(3):828-833.

8. Voulgaris E, Pentheroudakis G, Vassou A, Pavlidis N. Disseminated intravascular coagulation (DIC) and non-small cell lung cancer (NSCLC): report of a case and review of the literature. Lung Cancer. 2009;64(2): $247-249$.

9. Kobayashi N, Maekawa T, Takada M, Tanaka H, Gonmori H. Criteria for diagnosis of DIC based on the analysis of clinical and laboratory findings in 345 DIC patients collected by the Research Committee on DIC in Japan. Bibl Haematol. 1983;49:265-275.

10. Blom JW, Osanto S, Rosendaal FR. The risk of a venous thrombotic event in lung cancer patients: higher risk for adenocarcinoma than squamous cell carcinoma. J Thromb Haemost. 2004;2(10):1760-1765.

11. Shao B, Wahrenbrock MG, Yao L, et al. Carcinoma mucins trigger reciprocal activation of platelets and neutrophils in a murine model of Trousseau syndrome. Blood. 2011;118(15):4015-4023.
12. Pinzon R, Drewinko B, Trujillo JM, Guinee V, Giacco G. Pancreatic carcinoma and Trousseau's syndrome: experience at a large cancer center. J Clin Oncol. 1986;4(4):509-514.

13. Al-Mondhiry H. Disseminated intravascular coagulation: experience in a major cancer center. Thromb Diath Haemorrh. 1975;34(1): 181-193.

14. Sack GH Jr, Levin J, Bell WR. Trousseau's syndrome and other manifestations of chronic disseminated coagulopathy in patients with neoplasms: clinical, pathophysiologic, and therapeutic features. Medicine (Baltimore). 1977;56(1):1-37.

15. Donati MB, Lorenzet R. Thrombosis and cancer: 40 years of research. Thromb Res. 2012;129(3):348-352.

16. Tanaka K, Imamura $T$. Incidence and clinicopathological significance of DIC in autopsy cases. Bibl Haematol. 1983;49:79-93.

17. Corrales-Rodriguez L, Blais N. Lung cancer associated venous thromboembolic disease: a comprehensive review. Lung Cancer. 2012; 75(1):1-8

18. Kinoshita T, Azuma K, Sasada T, et al. Chemotherapy for non-small cell lung cancer complicated by idiopathic interstitial pneumonia. Oncol Lett. 2012;4(3):477-482.

19. Kanaji N, Tadokoro A, Kita N, et al. Impact of idiopathic pulmonary fibrosis on advanced non-small cell lung cancer survival. J Cancer Res Clin Oncol. 2016;142(8):1855-1865.

20. Kanaji N, Sakai K, Ueda Y, et al. Peripheral-type small cell lung cancer is associated with better survival and higher frequency of interstitial lung disease. Lung Cancer. 2017;108:126-133.
Therapeutics and Clinical Risk Management

\section{Publish your work in this journal}

Therapeutics and Clinical Risk Management is an international, peerreviewed journal of clinical therapeutics and risk management, focusing on concise rapid reporting of clinical studies in all therapeutic areas, outcomes, safety, and programs for the effective, safe, and sustained use of medicines. This journal is indexed on PubMed Central, CAS,

\section{Dovepress}

EMBase, Scopus and the Elsevier Bibliographic databases. The manuscript management system is completely online and includes a very quick and fair peer-review system, which is all easy to use. Visit http://www.dovepress.com/testimonials.php to read real quotes from published authors. 